\title{
Anaphylaxis: subjective symptom reports of patients with a special focus on "near-death" experiences
}

\author{
Johannes Ring · Anna Maria Farschtschi · Martine Grosber · Knut Brockow
}

Received: 12 August 2020 / Accepted: 25 November 2020 / Published online: 21 April 2021

(C) The Author(s) 2021

\begin{abstract}
Summary Almost all anaphylactic reactions are associated with subjective symptoms, which are also referred to "prodromi", and are often not taken seriously. In 100 patients categorized with different severity grades, subjective symptoms were investigated in a personal interview with free/open questions regarding subjective feelings and symptoms (duration 5-90 min). After the interview, the patients were asked to complete a questionnaire about the exact occurrence of the reaction. Special focus was given to near-death experiences in severe reactions. Patients described feelings of "elevation", "looking at themselves from outside", "tunnel experiences" and "bright light". In the kinetics of the anaphylactic reaction, cutaneous symptoms were most often reported as the first or second symptom, while cardiovascular and airway symptoms were also reported as the 3rd, 4th or 5 th symptom. In $37 \%$ of the patients with severe reactions, everyday life has changed since suffering the anaphylactic episode.
\end{abstract}

Keywords Paresthesia - Ring and Messmer severity grade classification $\cdot$ Hypersensitivity, immediate . Allergic reaction · Quality of life

Prof. Dr. med. Dr. phil. J. Ring ( $\varangle)$ • A. M. Farschtschi •

K. Brockow

Department of Dermatology and Allergology

Biederstein, Technical University Munich (TUM),

Biedersteinerstraße 29, 80802 Munich, Germany

Johannes.ring@tum.de

M. Grosber

Department Dermatology, Free University Brussels,

Brussels, Belgium

\section{Introduction}

Anaphylaxis is an immediate-type allergic reaction with potentially life-threatening symptoms which typically affect various organ systems [14, 29]. This has led to small differences in the definition of anaphylaxis in various countries around the world $[6,13$, 20, 23-25, 29, 31, 38, 40].

The phenomenon of anaphylaxis has been described scientifically in experimental studies [26], although there are early descriptions in medical history of similar reactions [3, 30].

With today's objective and quantitative measurements, the subjective experiences of patients are often underestimated, although the characteristics of suffering of symptoms like headache, vertigo or abdominal pain can imply a strong impairment of quality of life [4].

Anaphylactic reactions are almost always associated with more or less pronounced subjective symptoms which were sometimes also characterized as "prodromi" preceding an anaphylaxis or "vegetative complaints" [15, 18, 22, 41, 43].

In the allergist's office, questionnaires are commonly used $[17,27]$ for history taking in patients with anaphylaxis. However, information that could be obtained from the lively descriptions of the events and the subjective feelings by the patients may be lost.

It was the aim of this study to describe-in selected patients with different degrees of severity of anaphylaxis-the subjective experiences in the timely course of anaphylaxis and also describe the psychologic burden of patients with anaphylaxis. A special focus was placed on so-called frontier or near-death experiences $[1,5,11,35]$. 


\section{Patients and methods}

A total of 100 patients of the Department of Dermatology and Allergy Biederstein of the Technical University Munich from 2008-2010 were selected; the aim was to include cases with various degrees of severity. Patients with grade IV anaphylaxis had to be selected over a longer time frame and were specially contacted. The interviews were performed in the years 2010-2013.

A total of 67 women and 33 men (age range 16-88 years, mean 51.2 years) were included. The most important clinical data including the severity grades were taken from the patient files. The grading of severity was routinely done according the classification of Ring and Messmer [33]:

- Grade I: only skin symptoms

- Grade II: measurable but no life-threatening symptoms and various organ systems (airways, cardiovascular, gastrointestinal)

- Grade III: shock or loss of consciousness

- Grade IV: cardiac and/or respiratory arrest

In patients with more than one anaphylactic episode, the symptoms of the most severe reaction were taken. In all, $27 \%$ of the patients had suffered three or more episodes of anaphylaxis.

All patients were asked for a personal interview; 56 interviews were conducted by telephone. German language was no problem for the participants interviewed. The length of time the patients needed to tell about their experiences and symptoms ranged between $5 \mathrm{~min}$ and $1.5 \mathrm{~h}$. The patients were only interrupted when there were difficulties in understanding or unclear descriptions.

When the patients asked, "What do you actually want to know?" the answer was "Please just tell us what you experienced and what you were feeling!"

After the oral interviews were completed, the patients received the questionnaires in which they wrote the most important demographic data, the occurrence

Table 1 Elicitors of anaphylactic reactions in 100 patients with various severity grades (in \%)

\begin{tabular}{l|l}
\hline Insect stings & 64 \\
\hline Drugs & 20 \\
\hline Foods & 6 \\
\hline Summation anaphylaxis & 4 \\
\hline Unknown elicitors & 6 \\
\hline Sum & 100
\end{tabular}

Table 2 Mentioning of "prodromi" in the questionnaire (in \%)

\begin{tabular}{|l|l|}
\hline Paresthesias tongue/mouth & 33.8 \\
\hline Paresthesias hand/foot & 26.2 \\
\hline Abnormal taste on tongue & 10.0 \\
\hline Aura & 10.0 \\
\hline Other unpleasant sensations & 20.0 \\
\hline
\end{tabular}

of other diseases especially other allergies, social status, occupation as well as the actual events and characteristics of the anaphylactic reaction.

The symptoms mentioned by the patients were grouped according to the timely appearance from first symptom to fifth symptom.

Patients with very severe anaphylaxis who experienced so-called "frontier" or "near-death" experiences $[5,11]$ received special attention.

The program SPSS (version 22, IBM, Armonk, NY, USA) was used for statistical analysis.

\section{Results}

\section{Severity grades and elicitors}

In the 100 patients the following severity grades were observed:

- Grade I: $16 \%$

- Grade II: $34 \%$

- Grade III: $34 \%$

- Grade IV: $16 \%$.

The most common elicitors of anaphylaxis are listed in Table 1.

\section{Symptomatology}

As prodromal symptoms the patients mentioned "paresthesias on hands and feet", "paresthesias on the tongue or in the mouth", "special taste on the tongue" as well as "feeling an aura" or other complaints (Table 2).

The major symptoms recalled (most severe symptomatology in the patient's memory) are enlisted in Table 3.

In the timely appearance of symptoms, $53 \%$ of the patients mentioned cutaneous symptoms as the first symptom, $26 \%$ cardiovascular symptoms, $10 \%$ respiratory, $6 \%$ gastrointestinal and $5 \%$ other symptoms.

Table 3 Major symptoms (most severe symptomatology) in the experience of the patients $(n=100)$ with varying severity of anaphylaxis

\begin{tabular}{|l|l|}
\hline Symptoms & Frequency (in \%) \\
\hline Loss of consciousness & 21 \\
\hline Swelling of upper airways & 14 \\
\hline Dyspnea & 12 \\
\hline $\begin{array}{l}\text { Vegetative symptoms (excessive sweating, urinary inconti- } \\
\text { nence) }\end{array}$ & 7 \\
\hline Wheals & 7 \\
\hline Vomiting & 7 \\
\hline Tachycardia & 9 \\
\hline Nausea & 5 \\
\hline Significant drop in blood pressure & 7 \\
\hline Diarrhea & 2 \\
\hline Flush & 2 \\
\hline Itch & 2 \\
\hline
\end{tabular}


Also when looking at the second symptoms, cutaneous signs were the first to be mentioned with $42.5 \%$, then followed by cardiovascular symptoms $26.4 \%$, respiratory $19.5 \%$, gastrointestinal $9.2 \%$ and others $2.3 \%$. Most patients described up to three symptom constellations, only $43 \%$ mentioned 4 or 5 symptoms which were characterized more frequently as acute loss of consciousness in $21 \%$, breathing complaints in the upper airways in $14 \%$, dyspnea in $12 \%$, tachycardia in 9\% and vegetative symptoms (excessive sweat attack, involuntary urination or stool discharge; Table 4).

In the kinetics and timely occurrence of various symptoms, cutaneous symptoms dominated at the beginning, while cardiovascular and respiratory symptoms only appeared as the third or fourth symptom. There were differences with less recollections of prodromi between the spontaneous description in the interview and in answers to the questionnaire (Table 2).

\section{Frontier or near-death experiences}

Of all patients, $11 \%$ spontaneously mentioned having suffered from "fear", all from severity grade III and grade IV. A total of 17 patients mentioned "frontier" or "near-death" experiences, among them 12 patients with severity grade III and 5 patients with grade IV.

Descriptions of patients' frontier experiences included among others "pleasant feeling" or "loss of anxiety". Patients with grade III were able to report more intensively about these experiences than patients with grade IV in which loss of consciousness often occurred rapidly. In patients with grade III, loss of consciousness was mentioned only as 3rd, 4 th or 5 th symptoms by the patients.
The experiences described are listed in Table 5 and range from a feeling of "seeing yourself from outside your body", "feeling of floating", feeling of "attending one's own funeral" or "meeting deceased persons" to the "feeling of a tunnel" and the feeling "I don't want to go back".

Patients with frontier experiences did not differ from other patients with anaphylaxis with regard to concomitant diseases, other allergic disorders or elicitors. In those patients, $10 \%$ suffered from cardiovascular or metabolic diseases. When asked whether their life had changed since the anaphylactic reactions, this was answered with "yes" by $24 \%$ of patients without frontier experiences, while in patients with frontier experiences $35 \%$ reported a dramatic change in their everyday life. In logistic regression there was a 2.3-fold increased probability of an altered attitude to life in patients with frontier experiences compared to the rest.

\section{Feelings of anxiousness}

In the questionnaire a scale from 1-10 was offered to note feelings of anxiousness $(0=$ no anxiousness, $10=$ maximal fear). Most patients noted (50\%) feelings of anxiousness of severity grade $5,38 \%$ strong or very strong fear. Eleven patients even suffered from imminent fear of death.

Among vegetative complaints, urination in $10 \%$, defecation in $10 \%$ and sweating attacks in $7 \%$ were noted.

Table 4 Timely occurrence of symptoms observed by patients suffering from anaphylaxis (1st symptom to ... 5th symptom) (absolute numbers)

\begin{tabular}{|l|l|l|l|l|l|}
\hline Organ & 1st Symptom & 2nd Symptom & 3rd Symptom & 4th Symptom & 5th Symptom \\
\hline Number of patients & $n=100$ & $n=87$ & $n=62$ & $n=43$ & $n=20$ \\
\hline Cutaneous & 53 & 37 & 21 & 6 & 1 \\
\hline Cardiovascular & 26 & 23 & 18 & 20 & 9 \\
\hline Airways & 10 & 17 & 11 & 11 & 8 \\
\hline Gastrointestinal & 6 & 8 & 5 & 6 & 2 \\
\hline Others & 5 & 2 & 7 & 0 & 0 \\
\hline
\end{tabular}

Table 5 Frontier or near-death experiences in patients with high severity grades of anaphylaxis $(n=17$, grade III $=12$, grade $\mathrm{IV}=5$ )

\begin{tabular}{|c|c|c|c|}
\hline Experiences & Total (in \%) & Grade III (in \%) & Grade IV (in \%) \\
\hline "Pleasant feeling, loss of anxiety" & 94.1 & 75 & 25 \\
\hline "I don't want to go back" & 29.4 & 100 & 0 \\
\hline "Feeling of floating" & 23.5 & 100 & 0 \\
\hline "Seeing oneself from outside the body" & 23.5 & 50 & 50 \\
\hline "Tunnel experience" & 17.6 & 100 & 0 \\
\hline "Meeting deceased persons" & 5.9 & 0 & 100 \\
\hline "Attend your own funeral" & 11.8 & 0 & 100 \\
\hline
\end{tabular}


Selected examples of subjective symptomatology of patients with various severity grades of anaphylaxis

\section{Severity grade I, male, 56 years}

"I was stung by a wasp-most likely-I could not see the insect, but I felt a sting on my elbow. Shortly thereafter there was mild itching in the groin and my throat began to swell. After 15 min the itch migrated up to the hands, face and neck region. My wife and friends observed swelling of my face and thought that this was possibly an allergy. I also had the increasing feeling that my face was swelling more and more. My hands started to itch and I had a 'funny' feeling, like prickling when you have ridden a bicycle for a longer period of time. After about $30 \mathrm{~min}$, we went to the hospital where I received an infusion".

\section{Severity grade I, female, 45 years}

"I was working in the garden, suddenly there was an itch on my back like after a mosquito bite, then my whole body began itching and I got 'pustules' all over my body and I was totally red. Then I became frantic and at the same time lethargic and suffered from tremendous anxiety. It was as if I would go crazy - as if I had ants on my whole body".

\section{Severity grade II, male, 55 years}

"I was mowing the grass when I was stung by a wasp in my heel. I did not think much about it. After 20 min, I became nauseous, it felt like a strong wave of heat came over me and my head became very hot. I could actually feel my heartbeat in my head. My heart was racing; I had the feeling I had to lay down. I became breathless and had a feeling of tightness in my chest and shallow breathing; I felt as if I was swelling up".

\section{Severity grade II, female 41 years}

"I had a bad cold; therefore I took an analgesic (metamizole). I don't like tablets. I took them in the evening. The next morning I felt 'prickling' in the feet; they were red as a lobster. When I tried to get up my cardiovascular system broke down. I read the leaflet in the package and I was dizzy. My whole body was red, even under my underpants. I called the paramedics who came immediately".

\section{Severity grade II, male, 56 years}

"What should I say? I had dyspnea, itching, redness of the skin and a numb tongue. First I became red, then the scalp and my whole body was itching; I thought what is happening? Then everything began to swell. My tongue was feeling like the tongue of a cow, like a giant tongue. Then my throat starting to swell and close. I tried to breathe intensively because I thought I would suffocate. Then-thank God-the emergency paramedics arrived".

\section{Severity grade III, male, 72 years}

"I was cutting branches at the fence in the garden when something stung me, but I continued to work. Suddenly I had a headache; I thought my head was exploding! I left my equipment and went to my wife; she had me lay on the sofa, then I lost consciousness. From this point on, I was gone and felt that 'that is how it feels to die, this is the end!"”

\section{Severity grade III, female, 45 years}

"I had taken antibiotics for ten days, and had a slight rash and wheals; suddenly they became larger and larger. They were not really itchy and not painful. It was just a funny feeling. I did not feel well at all and went to bed and woke up and I felt worse; the rash became worse and worse, especially on my chest, upper thighs and legs. I felt very hot, swollen and I had tightness in my chest and was breathless. Then I went back to bed and I lost consciousness. My husband brought me to the doctor. I had to pull myself together; I was completely exhausted and my whole body was freezing”.

\section{Severity grade III, female, 31 years}

"Sometime in November something was moving in my hair, I wanted to chase it away and I was stung on the neck. I was with my parents, they were about to leave. I knew from the beginning that something was wrong. I became very cold and I felt as if a venom was spreading over my head and my spine like a cold fluid. My mother asked, 'Is something wrong with your head?' My parents were not amused because they were already late. I asked them to please stay. I laid down on the sofa. All of a sudden, all my joints started itching. My mother looked at me quite worried and asked, 'What is wrong with your face?' Obviously I was very swollen. I felt very bad and nauseated; I wanted to vomit but I couldn't. It was like when you have drunk too much and want to vomit because you know that things will improve. Then we went to the family physician who also looked very concerned and I was anxious because both of them looked so worried. I don't remember anything about the ride to the hospital. The most disturbing memory was when I realized waking up in my bed in the emergency room and my mother was sitting next me and holding my hand and I said, 'Mommy, mommy I love you', only then did I notice that it was my father, and never in my life had I mixed up my mother with my father. At this moment, I became very afraid and I wondered, 'What is wrong now?' During the course of the day, I recovered slowly".

\section{Patients with frontier/near-death experiences}

\section{Severity grade III, female 38 years}

"We attended the Oktoberfest (large beer festival in Munich), when a bee stung my wrist, the pain radiated into my right shoulder. I became increasingly 
quiet and 'shy' so that my husband brought me to the hospital. Although I insisted that this is only a bee sting, the physicians in the emergency room started to run around and ask, 'Would you like to lay down?' I said, 'No, everything is o.k., I was only stung by a bee', then I collapsed. The physician caressed my cheeks again and again and said, 'stay here, stay here, stay here!' I only thought, 'Leave me in peace; everything is so hectic'. I was feeling just fine, like in space without gravity, like on a cloud, far from the rest of the world, only with a grey fog or veil. Totally relaxed and calm, I only wanted to have my peace and sleep and thought about nothing, no family, no kids, everything was unimportant, I only wanted my peace ...."

\section{Severity grade III, male 51 years}

"I never had problems with allergy and have been stung by wasps and bees quite often, but nothing had ever happened. There was a hornet in the house and I wanted to take it outside, but it didn't like this and stung me twice. At first I didn't take it seriously but then my whole body began to itch and within minutes I had pustules all over. My wife said, 'You have elephant ears'. Then all of a sudden I couldn't breathe and I could just say, 'Okay, this is something worse, call the emergency doctor'. Then I was gone. From this time on I only saw myself from outside my body at a distance of five meters. Somehow I realized that they were doing something to me. You start to be the observer of your own situation until I finally woke up in the hospital. There was no panic, it was 'totally relaxed, easy and found everything just interesting'”.

\section{Severity grade IV, female 44 years}

"I had a prolapsed disk in my back and went to the doctor because of back pain who sent me to the orthopedic specialist. He gave me an injection of lidocaine and triamcinolone crystal suspension. Oh no! I am not well-and then I was gone. I felt warmth in my neck and after 2-3 min I was gone. From this time on, I was in coma over 13 days. It felt as if I had to lay in the cellar that had a 'clay floor' like my grandfather had to store potatoes. Behind me on the wall there were 4 clocks-probably the many instruments in the hospital. There were digital displays and I knew that when they counted down to zero, this would be my death. Everything was grey and on the ceiling there was 'metal grid', exactly the same as the one I saw 18 months later in the department store at IKEA (when I saw it I had to run out of the store crying). It was a very beautiful room in the cellar. My parents and both my kids were also there. My daughter was asked questions all the time and I thought they wanted to corrupt her and to take her away from me. But my daughter 'stood firm', she repeated again and again she would stay with mama. Here I have to add that my daughter is extremely fixed on me. My husband committed suicide when I was pregnant with her. She doesn't want to do anything without me.
Both my children and my parents, who were laying on the metal grid in the ceiling, tried again and again to reach my hands; every time when their hands were close to me, they were hit by an electric pulse and flew back. Maybe these were the several times when defibrillation was used. I knew that I had to die and I asked a good friend to get a coffin-a very simple metal coffin. He came back without a coffin and I was angry. He said, 'You will not die'. All of a sudden one clock behind me showed the seconds and the other three were already at zero. I felt that I was about die. The fingers on my hands were dying one at a time. At the end I could only move my great toe and all of a sudden I was in heaven. I knew that I was in heaven because under me there was the sea and the beach and my house. My grandma was standing in front of me with a jacket which I had never seen before, but which my mother would give me a few days later. My grandma said, 'Come with me'-[I said,] 'I think you are crazy; what should I do with my kids? I won't come with you; please give me a piece of paper and a pencil; I have to write a note'. She gave me both and I started to write. I wrote on the paper, where the testament and other important documents would be found in my house. I threw the letter down to the beach. I knew it would arrive where it should. All of a sudden I saw a very bright light on the horizon. It was a face, a male face with long hair who said, 'Come with me!' I replied, 'You are crazy'. I was really angry. Then I woke up. I could continue to tell you about this for hours. Since this experience, I am not afraid of dying anymore".

\section{Discussion}

In agreement with the literature, we generally found cutaneous symptoms of anaphylaxis to occur early and in most of our patients.

The spontaneous descriptions from patients provide much more lively impressions with regard to the timely occurrence of symptoms compared to simply working with questionnaires [28, 29].

Special interest was given to patients with severe anaphylactic reactions grade III and grade IV with intense "near-death" experiences. These recollections correspond quite well to similar reports from intensive care medical situations or from neurosurgical patients $[1,5,10,12]$ with the feelings of "standing outside oneself", "tunnel experience" or "very bright light". It is of interest that the "near-death" experiences were often described with a positive feeling. There are only speculations about the mechanism of these experiences; stress-induced endorphin release and hypoxia-stimulated effects on the temporal lobe have been discussed $[5,10,29]$.

Also interesting is that the near-death experiences were especially pronounced in patients with grade III, i.e., loss of consciousness and shock without cardiac or respiratory arrest and therefore without a resusci- 
tation procedure [32, 34, 37]. It may be possible that consciousness is lost so rapidly in those with resuscitation that there are no memories. It makes sense that direct cardiac effects result in immediate collapse and loss of consciousness [2, 8, 16, 21, 24, 25, 28, 44].

In a catamnestic study, only $24 \%$ of patients described that the anaphylactic episode did change their life tremendously. However in severe reactions and patients with near-death experience 35\% felt that their daily life had dramatically changed.

About $40 \%$ of patients continue to suffer from severe or very strong anxiety of further anaphylactic episodes. It would be interesting to know whether panic-fear attacks developed later on.

Our study showed that in taking the allergy history it is extremely important to have time for the patients, listen and let them talk [7]. The methods of free interview in combination with objective gathering of data and analyses of questionnaires enriches the knowledge and the classification of anaphylactic reactions.

The elicitors and allergens reported corresponded to those reported in the literature $[19,36,39,42]$. Also therapeutic interventions were collected in the memories of some patients, e.g., administration of adrenaline or cardiac resuscitation with defibrillation $[9,32,34]$.

As allergies are often trivialized and not recognized as severe conditions by society and the environment of affected patients is not taken seriously by insurance companies, it is of great importance to stress the lifethreatening character of anaphylaxis with consequent anxiety and negative life experiences of many affected patients.

Funding Open Access funding enabled and organized by Projekt DEAL.

Conflict of interest J. Ring, A.M. Farschtschi, M. Grosber and $\mathrm{K}$. Brockow declare that they have no competing interests.

Open Access This article is licensed under a Creative Commons Attribution 4.0 International License, which permits use, sharing, adaptation, distribution and reproduction in any medium or format, as long as you give appropriate credit to the original author(s) and the source, provide a link to the Creative Commons licence, and indicate if changes were made. The images or other third party material in this article are included in the article's Creative Commons licence, unless indicated otherwise in a credit line to the material. If material is not included in the article's Creative Commons licence and your intended use is not permitted by statutory regulation or exceeds the permitted use, you will need to obtain permission directly from the copyright holder. To view a copy of this licence, visit http://creativecommons.org/licenses/by/4.0/.

\section{References}

1. Appleby ND. Near-death experiences. $\mathrm{Br}$ Med J. 1989;298:976-7.

2. Barnard JH. Studies of 400 Hymenoptera sting deaths in the United States. JAllergy Clin Immunol. 1973;52:659-64.

3. Bergmann KC, RingJ. History of allergy. Basel: Karger; 2014.
4. Beyer K, Eckermann O, Hompes S, Grabenhenrich L, Worm M. Anaphylaxis in an emergency setting-elicitors, therapy and incidence of severe allergic reactions. Allergy. 2012;67:1451-6.

5. Blackmore SJ. Near-death experiences. J Royal Soc Med. 1996;89:73-6.

6. Bochner BS, Lichtenstein LM. Anaphylaxis. N Engl J Med. 1991;324:1785-90.

7. BrockowK, Schallmayer S, Beyer K, Biedermann T, Fischer J, Gebert N, et al. Effects of a structured educational intervention on knowledge and emergency management in patients at risk for anaphylaxis. Allergy. 2015;70:227-35.

8. Delage C, Irey NS. Anaphylactic deaths: a clinicopathologic study of 43 cases. JForensic Sci. 1972;17:525-40.

9. Deutscher Rat für Wiederbelebung, editor. Reanimation 2015-Leiliniekompakt. 2015. pp. 132-53.

10. Engmann B. Near-death experiences: heavenly insight or human illusion? Heidelberg: Springer; 2014.

11. Ewald GE. ,Ich war tot'. Ein Naturwissenschaftler untersucht Nahtoderfahrungen. Augsburg: Pattloch; 1999.

12. French CC. Near-death experiences in cardiac arrest survivors. Prog Brain Res. 2015;150:351-67.

13. Johansson SGO, Bieber T, Dahl R, Friedmann PS, Lanier BQ, Lockey RF, et al. Revised nomenclature for allergy for global use: report of the Nomenclature Review Committee of the World Allergy Organization. J Allergy Clin Immunol. 2004;113:832-6.

14. Lee S, Hess EP, Lohse C, Gilani W, Chamberlain AM, Campbell RL. Trends, characteristics and incidence of anaphylaxie in 2001-2010: a population-based study. JAllergy Clin Immunol. 2017;139:182-8.

15. Lieberman P, Nicklas RA, Oppenheimer J, Kemp SF, Lang DM (eds.). The diagnosis and management of anaphylaxis practice parameter: 2010 Update. J. Allergy Clin. Immunol 2010; $126: 477-480$

16. Marone G, Patella V, de Crescenzo G, Genovese A, Adt M. Human heart mast cells in anaphylaxis and cardiovascular disease. Int Arch Allergy Immunol. 1995;107:72-5.

17. Mehl A, Wahn U, Niggemann B. Anaphylactic reactions in children-a questionnaire-based survey in Germany. Allergy. 2005;60:1440-5.

18. Mueller HL. Diagnosis and treatment of insect sensitivity. JAsthma Res. 1966;3:331-3.

19. Müller UR. Epidemiology of insect sting allergy. Monogr Allergy. 1993;31:131-46.

20. Muraro A, Roberts G, Clark A, et al. The management of anaphylaxis in childhood: position paper of the European academy of allergology and clinical immunology. Allergy. 2007;62:857-71.

21. Pavek K, Wegmann A, Nordström L, Schwander D. Cardiovascular and respiratory mechanisms in anaphylactic and anaphylactoid shock reactions. Klin Wochenschr. 1982;60:941-7.

22. Przybilla B, Ring J, Ruëff F. Anaphylaxie: Klinisches Bild und Diagnose. Hautarzt. 2007;58:1025-31.

23. Przybilla B, RuëffF, Walker B, Räwer HC, Aberer W, Bauer CP, et al. Diagnose und Therapie der Bienen- und Wespengiftallergie. Allergo J.2011;20:318-39.

24. Pumphrey RS. Lessons for management of anaphylaxis from a study of fatal reactions. Clin Exp Allergy. 2000;30:1144-50.

25. Pumphrey R. Anaphylaxis: can we tell who is at risk of a fatal reaction? Curr Opin Allergy Clin Immunol. 2004;4:285-90.

26. Richet C. De l'anaphylaxie au sensibilité croissante des organismes á des doses sucessives de poison. Arch Fisiol. 1904;1:129-42. 
27. Ring J. Angewandte Allergologie. 3rd ed. München: Urban undVogel; 2004.

28. Ring J.Anaphylaktoide Reaktionen. Berlin: Springer; 1978.

29. RingJ, editor. Anaphylaxis. Basel: Karger; 2010.

30. Ring J, Behrendt H, de Weck A. History and classification of anaphylaxis. Chem Immunol Allergy. 2010;95:1-11.

31. Ring J, Beyer K, Biedermann T, Bircher A, Duda D, Fischer J, et al. Acute treatment and management of anaphylaxis. Allergo J Int. 2014;23:96-112.

32. RingJ, KlimekL, Worm M.Adrenalin in derAkutbehandlung der Anaphylaxie. Dtsch Arztebl Int. 2018;115:528-34.

33. Ring J, Messmer K. Incidence and severity of anaphylactoid reactions to colloid volume substitutes. Lancet. 1977;309:466-9.

34. Ring J, Beyer K, Biedermann T, Bircher A, Fischer M, Fuchs $\mathrm{T}$, et al. Acute treatment and management of anaphylaxis-update 2021. Allergo J Int. 2021;30:1-25. https://doi.org/10.1007/s40629-020-00158-y

35. Ring K. Life at death: a scientific investigation of the neardeath experience. NewYork: Quill; 1982.

36. Rohrer CL, Pichler WJ, Helbling A. Anaphylaxie: Klinik, Ätiologie und Verlauf bei 118 Patienten. Schweiz Med Wochenschr. 1998;128:53-63.

37. Ruëff F, Przybilla B, Bilo MB, Müller U, Scheibl F, Aberer W, et al. Predictors of severe systemic anaphylactic reactions in pattents with hymenoptera venom allergy: importance of baseline serum tryptase. J. Allergy Clin. Immunol. 2009; 124:1047-54.

38. Sampson HA, Muñoz-Furlong A, Campbell RL, Adkinson NF, Bock SA, Branum A, et al. Second symposium on the definition and management of anaphylaxis: summary report-Second National Institute of Allergy and Infectious Disease/Food Allergy and Anaphylaxis Network symposium. JAllergy Clin Immunol. 2006;117:391-7.

39. Sheikh A, Hippisley-Cox J, Newton J, Fenty J. Trends in national incidence, lifetime prevalence and adrenaline prescribing for anaphylaxis in England. J R Soc Med. 2008;101:139-43.

40. Simons FE, Ardusso LR, Bilò MB, El-Gamal YM, Ledford DK, Ring J, et al. World Allergy Organization anaphylaxis guidelines: summary. JAllergy Clin Immunol. 2011;127:587-93.

41. Webb L, Lieberman P. Anaphylaxis: a review of 601 cases. Ann Allergy Asthma Immunol. 2006;97:39-43.

42. Worm M, Eckermann O, Dölle S, Aberer W, Beyer K, Hawranek T, et al. Auslöser und Therapie der Anaphylaxie. Dtsch Arztebl. 2014;111:367-75.

43. Worm M, Edenharter G, Rueff F, et al. Symptom profile and risk factors of anaphylaxis in Central Europe. Allergy. 2012;67:691-8.

44. Vincent JL, De Backer D. Circulatory shock. N Engl J Med. 2013;369:1726-34. 